\title{
EFFICACY OF EPIDURAL 0.5\% ROPIVACAINE WITH FENTANYL COMPARED TO EPIDURAL 0.5\% BUPIVACAINE WITH FENTANYL FOR LSCS
}

\author{
B. Sowbhagya Lakshmi1, M. Santhi Sree ${ }^{2}$
}

1 Professor and HOD, Department of Anaesthesia, Rangaraya Medical College, Kakinada.

${ }_{2}^{2}$ Associate Professor, Department of Anaesthesia, Siddhartha Medical College, Vijayawada.

\begin{tabular}{l}
\hline ABSTRACT \\
BACKGROUND \\
The combination of local anaesthetics with adjuvants is getting more popular for better post-operative analgesia. Ropivacaine, s- \\
enantiomer produces neural blockade with less cardiovascular toxicity than bupivacaine. Therefore, in this study bupivacaine was \\
compared with ropivacaine with fentanyl as adjuvant. \\
The aim of this study was to compare the efficacy of two different solutions of epidural ropivacaine with fentanyl and epidural \\
bupivacaine with fentanyl.
\end{tabular}

\section{MATERIALS AND METHODS}

This was a prospective, randomised, controlled, double-blind study carried out in parturients undergoing elective caesarean section with singleton foetus. A total number of 50 parturients in the age group of 20 - 35 years of ASA Grade I and II scheduled for elective caesarean section under epidural anaesthesia were divided into two groups using computer generated randomisation. Group RF were given $18 \mathrm{~mL}$ of $0.5 \%$ Ropivacaine with $25 \mu \mathrm{g}$ fentanyl and Group BF were given $18 \mathrm{~mL}$ of $0.5 \%$ Bupivacaine with 25 $\mu \mathrm{g}$ fentanyl. Sensory block, motor block, duration of analgesia, maternal effects and foetal outcome are evaluated.

\section{RESULTS}

Onset of sensory block was faster with ropivacaine-fentanyl group compared with bupivacaine-fentanyl group. Duration of analgesia was prolonged in bupivacaine-fentanyl group. Cardiovascular side effects are less with RF group.

\section{CONCLUSION}

Ropivacaine with fentanyl proved to be equally efficacious when compared with bupivacaine-fentanyl group with good cardiovascular stability with ropivacaine-fentanyl group and provided excellent post-operative analgesia.

\section{KEYWORDS}

Bupivacaine, Ropivacaine, Epidural Analgesia, Fentanyl.

HOW TO CITE THIS ARTICLE: Lakshmi BS, Sree MS. Efficacy of epidural 0.5\% ropivacaine with fentanyl compared to epidural 0.5\% bupivacaine with fentanyl for LSCS. J. Evolution Med. Dent. Sci. 2017;6(93):6747-6750, DOI: 10.14260/jemds/2017/1461

\section{BACKGROUND}

Epidural anaesthesia with local anaesthetics alone or in combination with opioids is an established anaesthetic technique for caesarean section.1,2 The role of epidural anaesthesia and analgesia in reducing incidence and severity of perioperative physiologic derangements in addition to relieving pain has been reported in several studies. Local anaesthetics that are in common use are lignocaine, bupivacaine and ropivacaine. Epidural lignocaine produces shorter duration of block and also can cause transient neurological symptoms, hence has been withdrawn. Bupivacaine produces profound motor block of longer duration and also had adverse effects on cardiovascular system.3,4 Ropivacaine an amide local anaesthetic has been introduced and used successfully to provide epidural analgesia for labouring women, caesarean delivery and postoperative analgesia. ${ }^{5}$

'Financial or Other Competing Interest': None.

Submission 13-09-2017, Peer Review 21-11-2017,

Acceptance 27-11-2017, Published 11-12-2017.

Corresponding Author:

Dr. M. Santhi Sree,

D. No. 13-2-2, Sai Krishna Towers,

D1 Apts., Latchiraju Street,

Kakinada-583002, E. G. Dt,

E-mail: santhisreemulam@gmail.com

DOI: $10.14260 /$ jemds $/ 2017 / 1461$

\section{(c) (i) $(5)$}

Ropivacaine has an improved safety profile over bupivacaine with reduced central nervous system and cardiotoxic potential and hence gaining favour. Various adjuvants in addition to opioids have been used epidurally to prolong analgesia and reduce the incidence of adverse events observed when opioids are used alone. Because of its greater lipophilic nature, fentanyl offers advantage for epidural analgesia. The rapidity of analgesic effects of epidural fentanyl and relatively short duration of action makes it the drug of choice for post-operative acute pain. ${ }^{6}$ So epidural fentanyl in combination with local anaesthetics produce increased sensory block without increasing sympathetic block, while achieving satisfactory quality of epidural block at a much lower dose of local anaesthetic with negligible effects on foetus. Hence, we conducted a study to compare the efficacy of epidural bupivacaine with fentanyl and epidural ropivacaine with fentanyl on duration of analgesia, haemodynamic stability and side effects in parturients undergoing LSCS.

\section{Aim of Study}

Aim of our study is to evaluate the analgesic efficacy of epidural bupivacaine with fentanyl and epidural ropivacaine with fentanyl for caesarean section.

\section{MATERIALS AND METHODS}

The present study was a prospective, randomised, doubleblinded comparative study conducted during June 2016 to 
December 2016. After obtaining Institutional Ethical Committee approval, and written and informed consent, 50 parturients of ASA Grade I and II aged between 20 - 35 years with singleton foetuses posted for elective caesarean section were enrolled for the study and divided into two groups by computer generated randomisation. The randomisation scheme was generated using the website Randomisation.com. Group assignment was enclosed in a sealed envelope to ensure concealment of allocation sequence. The sealed envelope was opened by an anaesthesiologist not involved in the study who then prepared the drug solution according to randomisation. The study was conducted in a double-blind fashion, such that the patient and the assessor were unaware of group allocation. The assessor was kept blinded during administration of drug. The sample size calculation was based on pilot study and duration of analgesia was taken as primary end point of the study. The mean duration of analgesia in Group RF was $174 \mathrm{mts}$ and in Group BF it was 189 mts with difference of 15 mts in mean duration of analgesia. The calculation assumed a standard deviation of 20 $m$ ts in duration of analgesia and with an alpha error of 0.05 and power of $80 \%$. The sample size was calculated as 28 in each group and with possible droupouts the sample size was taken as 25 in each group. Thorough pre-anaesthetic evaluation and investigations were carried out to find any associated illness. The study drug volume is $18 \mathrm{~mL}$ in both groups.

\section{Exclusion Criteria}

Patients for whom central neuraxial block was contraindicated and those with history of reaction to study drugs, on analgesic therapy, major hepatic, renal or cardiovascular dysfunction were excluded from the study. Patients were briefed before operation on visual analogue pain scale (VAS 0: No, 10: Worst pain ever).

Parturients were fasting for $6 \mathrm{hrs}$. and were premedicated with oral alprazolam at night. On arrival at the operating room, electrocardiogram, non-invasive blood pressure and pulse oximeter, monitoring were started. Baseline pulse rate, BP (systolic, diastolic, mean) and oxygen saturation were noted. An intravenous access was established and all the patients were preloaded with lactated Ringer's solution (10 mL/kg bd. Wt.). Under all aseptic precautions, epidural block was performed in the lateral decubitus position at $\mathrm{L}_{3}$ - $\mathrm{L}_{4}$ or $\mathrm{L}_{4}$ - $\mathrm{L}_{5}$ space with an 18-gauge Tuohy needle by midline approach. Epidural space was identified by loss of resistance to normal saline. After negative aspiration for blood and CSF, epidural catheter was threaded in cephalic direction, so that $3 \mathrm{~cm}$ of catheter was in space. Test dose of $3 \mathrm{~mL} 2 \%$ lignocaine with $15 \mathrm{mg}$ adrenaline was administered to confirm catheter position. After 3 mins, test drug $0.5 \%$ ropivacaine along with $25 \mu \mathrm{g}$ fentanyl was given to Group RF and $0.5 \%$ bupivacaine with $25 \mu \mathrm{g}$ to Group BF respectively. A left uterine displacement of $15^{\circ}$ was maintained. Sensory block was assessed bilaterally by using pinprick method and motor block was evaluated by using modified Bromage scale (Table I). Duration of sensory block is the time interval between maximum level achieved and thereafter every 10 mins till the sensory block regressed by two levels. Incision was made when sensory block reached T6. Induction to delivery time (ID interval) and uterine incision time were recorded. Oxytocin $15^{\mathrm{u}}$ were given as infusion after delivery of baby. Motor block was assessed at 5 mins interval according to Bromage scale. Duration of motor block was defined as the time of absence of knee flexion to return of knee flexion. Sedation was assessed intra- and postoperatively for $24 \mathrm{hrs}$. using the sedation 4-point score (Table II) and the highest achieved was taken into consideration. Hypotension was taken as systolic BP $<100 \mathrm{mmHg}$. Heart rate of $<50$ and $>140$ was considered abnormal. Hypotension was initially treated with rapid infusion of fluids and intravenous ephedrine was supplemented if the systolic BP persisted below $100 \mathrm{mmHg}$ for a period of $1 \mathrm{~min}$. Bradycardia was treated with $0.6 \mathrm{mg}$ atropine intravenously. Criteria for respiratory inadequacy were taken as an oxygen saturation $<94 \%$, a respiratory rate of $<12 /$ mins or the need to support ventilation. Neonatal outcome was assessed by neonatologist who was blinded to the study drug. Apgar score at 5 mins $<7$ and umbilical arterial $\mathrm{pH}$ of $<7.2$ were taken as abnormal. Post-operatively, parturients were monitored in the post anaesthesia care unit (PACU) for $24 \mathrm{hrs}$. Total duration of analgesia was calculated from onset of sensory block (T6) to the end of analgesia, that is pain score of 3 or more on the VAS ( 0 - no pain, 2 - 4 mild pain, 5 - 7 moderate pain, 8 - 10 worst pain). Incidence of nausea, vomiting, pruritus and sedation was observed for 24 hrs. postoperatively. Urinary retention was not assessed, as all parturients were catheterised for $24 \mathrm{hrs}$.

\section{Statistical Analysis}

The data was compiled and analysed statistically by using student's ' $t$ ' test and a ' $p$ ' value of $<0.05$ was considered as significant and $\mathrm{p}<0.001$ was considered as highly significant. All the scores in our study were analysed by using the student's ' $t$ ' test and standard error of difference between the two means and chi-square test. Statistical analysis was done by using GraphPad prism software version 7.03 for windows (Inc., California Corporation).

\section{RESULTS}

The groups were comparable in ASA grading, age, height, weight, baseline BP, pulse rate, respiratory rate and oxygen saturation (Table III) (Bar Diagram 1). Onset of sensory block was little faster in the RF group compared to BF group $(7.2+$ $3 \mathrm{mts}$ vs $9.3+5 \mathrm{mts}$ ) with a p value of 0.0928 , which is not significant. Duration of analgesia in Group RF is $2.9+1.2 \mathrm{hrs}$., while in Group BF it is $3.1+1.5$ hrs. indicating a little prolongation of analgesia in Group BF when compared to Group RF (Table IV) (Bar Diagram 2).

The BP, pulse rate, respiratory rate and oxygen saturation of all parturients were within normal limits intra-operatively and post-operatively. Three patients in Group BF showed transient hypotension (BP $<100 \mathrm{mmHg}$ systolic), which was managed by rapid infusion of fluids and single dose of ephedrine $6 \mathrm{mg}$ intravenously. No patients in Group RF had either bradycardia or tachycardia, while two patients had bradycardia in Group BF who were given injection atropine $0.6 \mathrm{mg}$ IV. Oxygen saturation and respiratory rate were within normal limits. APGAR score at 5 mins was above 7 and umbilical cord arterial blood PH was above 7.2 in all neonates in both groups. No one required mechanical ventilation, tracheal intubation or admission to ICU denoting good foetal outcome. There was no incidence of nausea and vomiting in both groups and pruritus needing no intervention was 
observed in two patients in Group RF and one patient in Group BF. Urinary retention could not be assessed as all parturients were catheterised. Sedation score appeared to be within 1 (arousable on verbal stimulation) in both groups.

\begin{tabular}{|c|c|}
\hline 0 & No motor block \\
\hline 1 & Inability to raise extended legs \\
\hline 2 & Inability to flex knees \\
\hline 3 & Inability to flex ankle joints \\
\hline \multicolumn{2}{|c|}{ Table I. Showing Bromage Scale } \\
\hline
\end{tabular}

\begin{tabular}{|c|c|}
\hline 0 & Awake and alert \\
\hline 1 & Mildly sedated, easily awakened \\
\hline 2 & Moderately sedated, awakened by shaking \\
\hline 3 & $\begin{array}{c}\text { Deeply sedated, difficult to be awakened by physical } \\
\text { stimulation }\end{array}$ \\
\hline \multicolumn{2}{|c|}{ Table II. Showing Sedation- 4 Point Scale } \\
\hline
\end{tabular}

\begin{tabular}{|c|c|c|c|}
\hline & $\begin{array}{c}\text { Group RF } \\
\mathbf{n = 2 5}\end{array}$ & $\begin{array}{c}\text { Group BF } \\
\mathbf{n = 2 5}\end{array}$ & P value \\
\hline Age in yrs. & $25.97 \pm 0.57$ & $25.68 \pm 0.54$ & 0.586 \\
\hline Weight (kg) & $65.92 \pm 1.35$ & $65.59 \pm 1.22$ & 0.774 \\
\hline Height (cm) & $157.88 \pm 0.69$ & $157.86 \pm 0.71$ & 0.334 \\
\hline ASA I, ASA II & 21,4 & 22,3 & 0.96 \\
\hline
\end{tabular}

Table III. Showing Patient's Characteristics (mean \pm SE)

\begin{tabular}{|c|c|c|c|}
\hline & Group RF & Group BF & P value \\
\hline Onset of sensory block & $7 \pm 3$ mins & $9 \pm 5$ mins & 0.0928 \\
\hline Duration of analgesia & $2.9 \pm 1.2 \mathrm{hrs}$. & $3.1 \pm 1 \mathrm{hrs}$. & 0.5419 \\
\hline $\begin{array}{c}\text { 2 segment regression } \\
\text { time }\end{array}$ & $69 \pm 12 \mathrm{mins}$ & $71 \pm 7$ & 0.4751 \\
\hline \multicolumn{3}{|c|}{ Table IV } \\
\hline
\end{tabular}
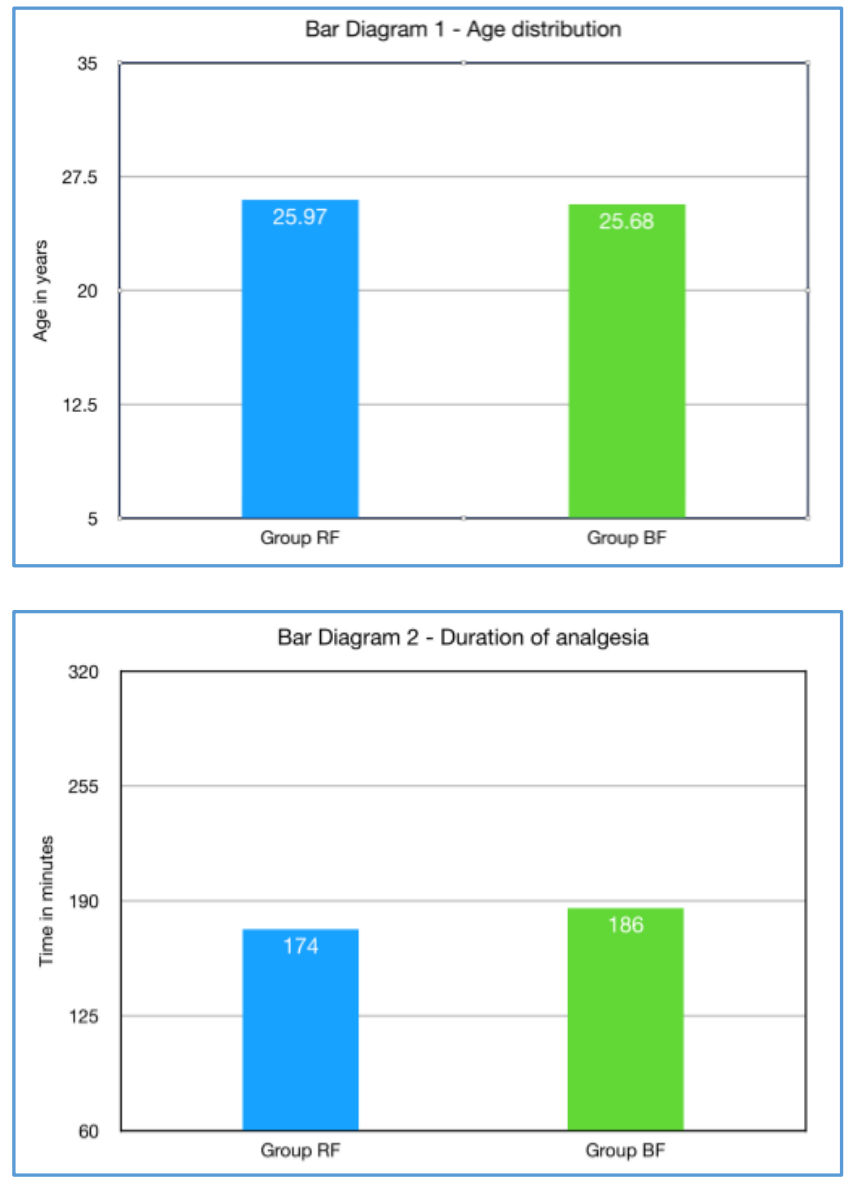

\section{DISCUSSION}

In the present study, ropivacaine with fentanyl and bupivacaine with fentanyl given epidurally provided effective analgesia for caesarean section. In the ropivacaine-fentanyl group the onset of analgesia was earlier than bupivacainefentanyl group and duration of analgesia was little higher in bupivacaine-fentanyl group. This was similar to the observation made by Hong et al in their study. ${ }^{7}$ Bupivacaine is longer acting amide group, which has been used as prime agent in epidural anaesthesia and also to provide postoperative pain relief. Ropivacaine is newer amide longer acting used nowadays as a prime agent due to its less side effects and better haemodynamic stability with less motor blockade. ${ }^{8,9}$ Bupivacaine when used in combination with an opioid analgesic was more effective than ropivacaine in terms of duration of analgesia. 10

The demand for bupivacaine was less and volume of drugs given in post-operative period was less as stated by study conducted by Peduto et al. ${ }^{11}$ Duration of analgesia was longer with bupivacaine-fentanyl group than with ropivacaine-fentanyl group as was seen in study conducted by Brown DL et al. We observed a little fall in systolic BP in bupivacaine-fentanyl group that could be explained by cardiotoxicity of bupivacaine. ${ }^{12}$ Haemodynamic stability was more in ropivacaine-fentanyl group, as there was a very small fall in mean blood pressure and heart rate which was stated by Brockway MS et al. ${ }^{13}$

The combination of local anaesthetic and opioids may effectively inhibit multiple areas of neuronal excitability. The possible mechanisms of opioids induced acceleration of sensory block is its property of blocking nerve conduction in spinal roots. The main concern about using a drug in pregnancy is its safety profile on the mother and foetus. The classical side effects of concern about neuraxial opioids are depression of ventilation, sedation, pruritus, nausea, vomiting and urinary retention. In our observation, only small number in both groups had pruritus of mild nature. Nausea and vomiting were not reported. Sedation if at all occurred was mild. Safety of neonate was established. In conclusion, Ropivacaine $0.5 \%$ with fentanyl and bupivacaine with fentanyl provided safe anaesthesia when given epidurally.

\section{CONCLUSION}

In the comparative study between $0.5 \%$ Ropivacaine and $0.5 \%$ Bupivacaine along with fentanyl as an adjuvant in each group, we observed the efficacy of post-operative epidural analgesia in patients undergoing elective LSCS. On the basis of statistical analysis, among the two local anaesthetics it may be concluded that-

a. Duration of analgesia was longer and better with Bupivacaine.

b. Quality of analgesia was better with Bupivacaine in comparison with Ropivacaine.

c. Haemodynamic cardiovascular stability was more with Ropivacaine when compared to Bupivacaine.

\section{REFERENCES}

[1] Griffin RP, Reynolds F. Extra dural anaesthethesia for caesarean section: a double blind comparison of $0.5 \%$ ropivacaine with $0.5 \%$ bupivacaine. $\mathrm{Br} \mathrm{J}$ Anaesth 1995;74(5):512-6. 
[2] Writer WD, Stienstra R, Eddleston JM, et al. Neonatal outcome and mode of delivery after epidural analgesia for labour with ropivacaine and bupivacaine: a prospective meta-analysis. $\mathrm{Br} \mathrm{J}$ Anaesth 1998;81(5):713-7.

[3] Arthur GR, Feldman HS, Covino BG. Comparative pharmacokinetics of bupivacaine and ropivacaine, a new amide local anesthetic. Anesth Analg 1988;67(11):1053-8.

[4] Katz JA, Bridenbaugh PO, Knarr DC, et al. Pharmacodynamics and pharmacokinetics of epidural ropivacaine in humans. Anesth Analg 1990;70(1):1621.

[5] Brown DL, Carpenter RL, Thompson GE. Comparison of $0.5 \%$ ropivacaine and $0.5 \%$ bupivacaine for epidural anaesthesia in patients undergoing lower extremity surgery. Anesthesiology 1990;72(4):633-6.

[6] Cherng CH, Wong CS, Ho ST. Epidural fentanyl speeds the onset of sensory block during epidural lidocaine anaesthesia. Reg Anesth \& Pain Med 2001;26(6):5236.

[7] Hong JY, Jee YS, Jeong HJ, et al. Effects of epidural fentanyl on speed and quality of block for emergency cesarean section in extending continuous epidural labour analgesia using ropivacaine and fentanyl. J Korean Med Sci 2010;25(2):287-92.
[8] Debon R, Chassard D, Duflo F, et al. Chronobiology of epidural ropivacaine: variation of furation of action related to the hour of administration. Anesthesiology 2002;96(3):542-5.

[9] Morton CP, Bloomfield S, Magnusson A, et al. Ropivacaine $0.75 \%$ for extradural anaesthesia in elective caesarean section: an open clinical and pharmacokinetic study in mother and neonate. $\mathrm{Br} \mathrm{J}$ Anaesth 1997;79(1):3-8.

[10] Morrison LM, Emanuelsson BM, McClure JH, et al. Efficacy and kinetics of extradural ropivacaine: comparison with bupivacaine. $\mathrm{Br} \mathrm{J}$ Anesth 1994;72(2):164-9.

[11] Peduto VA, Baroncini S, Montanini S, et al. A prospective, randomized, double-blind comparison of epidural levobupivacaine $0.5 \%$ with epidural ropivacaine $0.75 \%$ for lower limb procedures. European Journal Anaesthesiology 2003;20(12):97983.

[12] Liu S, Angel JM, Owens BD, et al. Effiects of epidural bupivacaine after thoracotomy. Reg Anesth 1995;20(4):303-10.

[13] Brockway MS, Bannister J, McClure JH, et al. Comparison of extradural ropivacaine and bupivacaine. Br J Anesth 1991;66(1):31-7. 